\title{
A Novel Reduction Strategy of Standby Power Loss in the Multi-Oscillated Current Resonant DC-DC Converter Considering Acoustic Noise Compatibility
}

\author{
Tadahiko SATO ${ }^{1,2}$, Hirofumi MATSUO ${ }^{2}$ and Hiroyuki OTA ${ }^{1}$ \\ 1) Fuji Electric Co., Ltd. \\ 2) Graduate School of Science and Technology, Nagasaki University \\ E-mail: sato-tadahiko@fujielectric.co.jp
}

\begin{abstract}
The current resonant type DC-DC converter employs generally the pulse frequency modulation and its magnetizing inductance is set relatively low. For this reason, the magnetizing current through the converter causes a power loss under the light load condition. To solve this problem, a multi-oscillated current resonant type DC-DC converter has been proposed and then the advantage of its control method has been clarified, which can reduce power loss under light load condition and keep low switching noise. This paper deals with a novel reduction strategy of standby power consumption of the converter. As a result, the standby power consumption under no load condition is achieved below $60 \mathrm{~mW}$ at $100 \mathrm{~V}$ AC input and $150 \mathrm{~mW}$ at $240 \mathrm{~V}$ AC input, respectively. Furthermore, it is clarified that the slope of the resonant current envelope at soft start and end function in the standby mode influence the acoustic noise from the converter.
\end{abstract}

Keywords; resonant converter, standby-power consumption, acoustic noise

\section{INTRODUCTION}

The current resonant type DC-DC converter, which has advantage of high efficiency, low noise and small size, is used widely in consumer electronics, telecommunication systems and so forth [1-12]. The pulse frequency modulation (PFM) is employed generally in this type of converter [1-12]. However, this type of converter has deteriorated problems, in which a magnetizing current through the converter causes a loss of power under the light load condition. Also, it is difficult to reduce power consumption under no load condition i.e. in the standby mode. So, it is necessary to use another isolated converter which is relatively large in order to reduce the standby mode power loss.

To solve these problems, a multi-oscillated current resonant DC-DC converter has been proposed [13-18]. It has been clarified in recent some papers that the high power efficiency (maximum one over 96\% in DC-DC section) is achieved under the condition from the light load by using the PWM and selfoscillation $[17,18]$.

This type converter has adopted the intermittently switching mode in the standby mode [15]. In generally, the function of intermittently switching is able to reduce power consumption, but it has a problem with the acoustic noise compatibility.

This paper presents a novel standby control strategy for the multi-oscillated current resonant DC-DC converter, which is superior to the former paper. Furthermore, the reduction of the power consumption in the standby mode is discussed with considering the acoustic noise compatibility.

\section{CIRCUIT CONFIGRATION}

Figure 1 and 2 show the proposed multi-oscillated current resonant DC-DC converter and the timing chart, respectively. This converter consists of a half-bridge circuit, whose switches $\mathrm{Q}_{1}$ and $\mathrm{Q}_{2}$ which consist of MOSFET, are operated by a multioscillated current resonant driven by an IC with pulse-width modulation (PWM), and an auxiliary winding $\mathrm{N}_{\mathrm{P} 2}$ of the transformer, respectively.

In this converter, a multi-chip power module which consists of a control IC and two MOSFETs into one package is adopted. Furthermore, a startup circuit which is connected to the input voltage of this converter is included in the control IC of this module. Therefore, PWB pattern is minimized than they are composed as all discrete devices.

In the Fig. 1, an $\mathrm{AC}$ input is converted to $\mathrm{DC}$ voltage through the AC-DC rectifier bridge and PFC circuit which is normally used a PFC control IC in former step of this converter.

The leakage inductance of transformer is included in $T_{r}$ (It is omitted in the figure). In the secondary side, a sub DC-DC converter is added for supplying the voltage to the system control (e.g. CPU and its peripheral). This sub DC-DC converter is also used in the standby mode. It is important to note that the isolation element is unnecessary such as AC-DC converter, in which its size is very small and the circuit configuration is very simple.

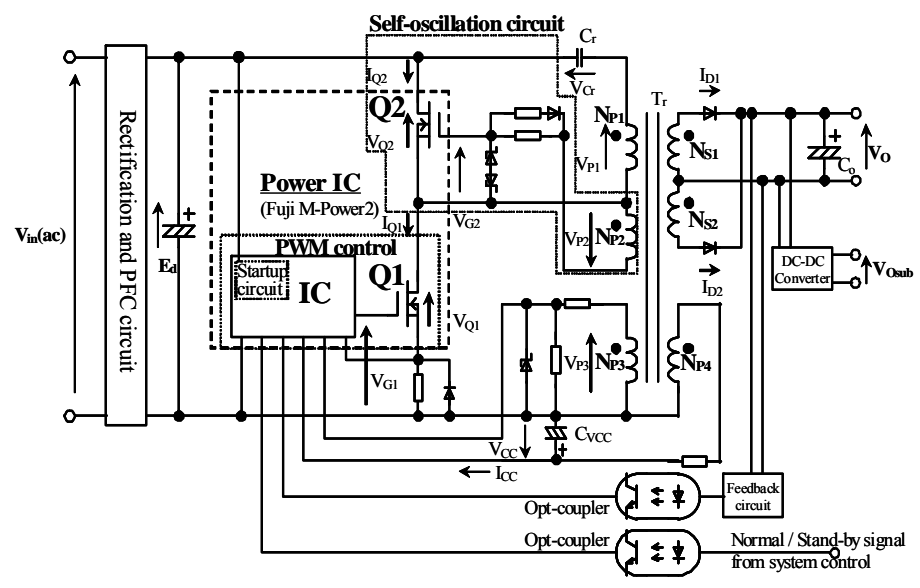

Fig. 1 Circuit configuration 
By applying a gate voltage to $\mathrm{Q}_{1}$ and $\mathrm{Q}_{2}$ at turn-on and turn-off, switching power losses are reduced due to the zerovoltage switching (ZVS) and zero-current switching (ZCS).

In the isolated transformer $T_{r}$, the primary winding $N_{P 1}$ is loosely coupled to the secondary windings $\mathrm{N}_{\mathrm{S} 1}$ and $\mathrm{N}_{\mathrm{S} 2}$, for in which the voltage of the leakage inductance is relatively large. Because of the resonant circuit with this leakage inductance and the resonant capacitor, the switching power losses of $Q_{1}$ and $\mathrm{Q}_{2}$ are reduced.

A winding of transformer $\mathrm{N}_{\mathrm{P} 3}$ is added for timing detection of $\mathrm{Q}_{1}$. The polarity of this winding is opposite to $\mathrm{N}_{\mathrm{P} 2}$, which is used to drive $\mathrm{Q}_{2}$. Moreover, the control IC turns $\mathrm{Q}_{1}$ off before $\mathrm{N}_{\mathrm{P} 3}$ turns to negative. Therefore this converter prevents arm short automatically.

In this converter, to realize the novel standby operation, the winding $\mathrm{N}_{\mathrm{P} 4}$ for the power supply $\mathrm{V}_{\mathrm{CC}}$ is coupled strongly to the secondary windings and it is electrically isolated from the secondary side. And the control IC detects the output voltage $\mathrm{V}_{\mathrm{O}}$ indirectly by observing $\mathrm{V}_{\mathrm{CC}}$ in the standby mode.

In the normal operation, the input voltage for this converter is regulated to $400 \mathrm{~V} \mathrm{DC}$ by PFC circuit. On the other hand, in the standby mode, the input voltage for this converter is varied from about 140 to $340 \mathrm{~V} \mathrm{DC}$ in universal input because a power supply to the PFC circuit is turned off for reducing power consumption.

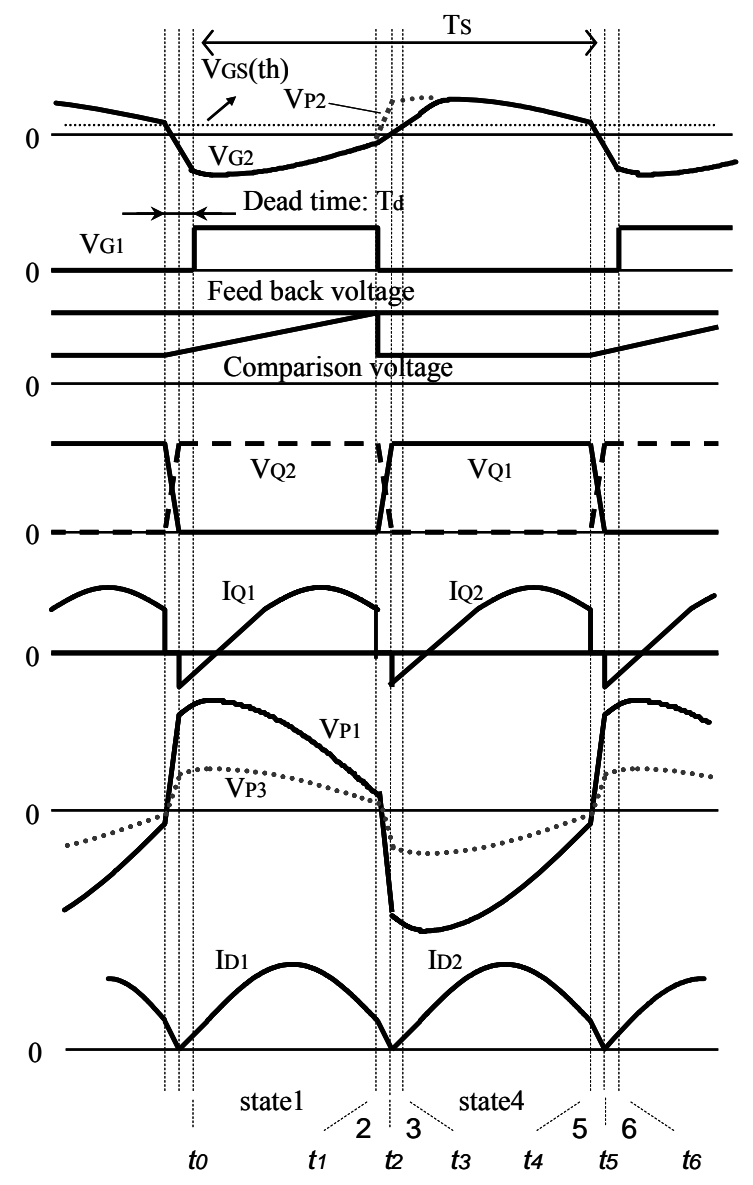

Fig. 2 Timing chart

\section{OPERATION PRINCIPLE}

\section{A. Basically Operating mode (Normal Mode)}

Figure 3 shows the equivalent circuits of the converter shown in Fig. 1, which is divided into eight behavior states. Taking into account the combination of the eight states of behavior, they are further divided into four operating modes [16].

Figure 4 shows the simulated waveforms of the current and voltage for the four operating modes. From the results, the op-

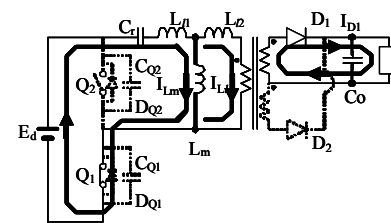

(a) state 1

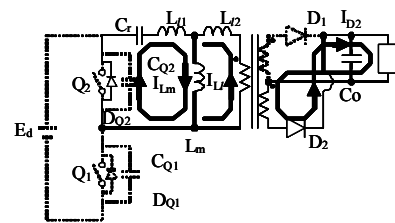

(c) state 3

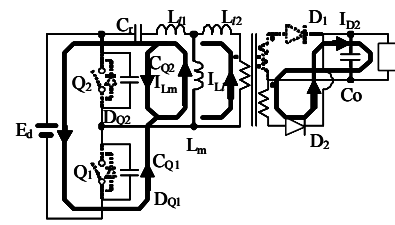

(e) state 5

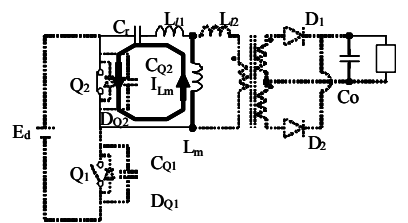

(g) state 7

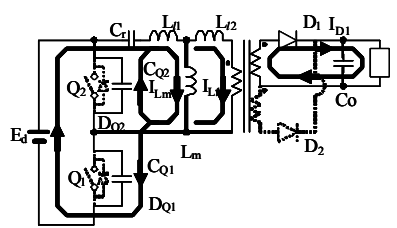

(b) state 2

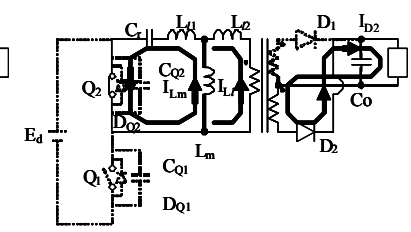

(d) state 4
Fig. 3 Equivalent circuits and operation states

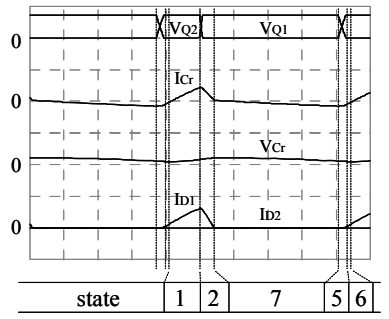

(a) Mode I

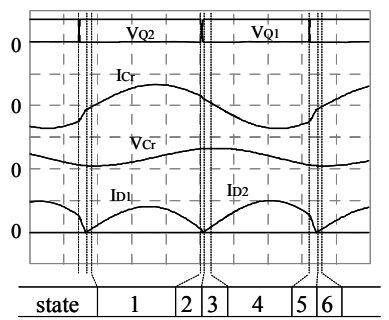

(c) Mode III
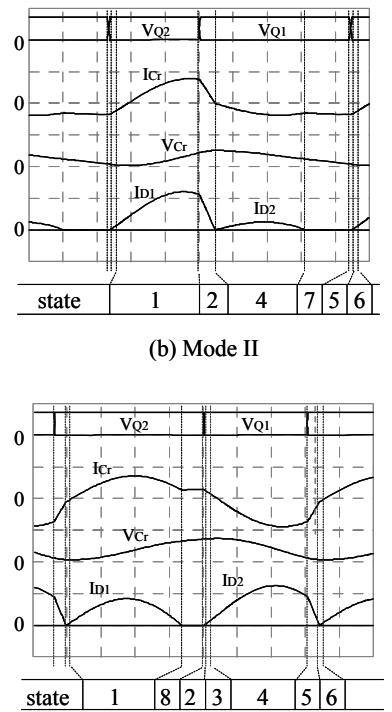

(d) Mode IV (b) Mode II

Fig. 4 Operation modes 
erating modes appear in the order of I, II, III and IV when the load current is varied from the light load to the heavy load.

The operating modes I and II mainly appear at light load. The energy in $C_{r}$ is discharged when the $Q_{1}$ turns off and $Q_{2}$ turns on, and charged by applying the output voltage $E_{d}$ of the $\mathrm{PFC}$ when the $\mathrm{Q}_{1}$ turns on and $\mathrm{Q}_{2}$ turn off. Therefore, the energy is discharged to the secondary side through the transformer. However, because of the magnetizing inductance $\mathrm{L}_{\mathrm{m}}$ is set relatively large when there is shortage of the energy discharged from $\mathrm{C}_{\mathrm{r}}$, operating state 7 appears, in which there is no discharging interval to the secondary side.

In the mode III, a ripple is reduced and smoothed by the leakage inductance $\mathrm{L}_{12}$ of the secondary winding and the output capacitor $\mathrm{C}_{\mathrm{o}}$ because the current flows continuously through $\mathrm{D}_{1}$ and $\mathrm{D}_{2}$, alternately.

The Mode IV appears when the duty ratio is almost over $50 \%$. In this mode, the state 8 appear where the power is not applied to the secondary side even when $\mathrm{Q}_{1}$ turns on.

\section{B. Standby Mode}

Figure 5 shows block diagram of control circuit that is related to standby function and figure 6 shows the on period of $\mathrm{Q}_{1}$ characteristic. In the standby mode, voltage $\mathrm{V}_{\mathrm{CS}}$ of a capacitor $\mathrm{C}_{\mathrm{CS}}$ determines the on period of $\mathrm{Q}_{1}$.

Figure 7 shows the timing chart of standby mode. In the standby mode, the system control in the secondary side releases the pulled-up connection to the reference voltage of the control IC (approximately 5V). Then the control IC discharges $\mathrm{C}_{\mathrm{CS}}$ with constant current $I_{C S}$, so the on-period of $Q_{1}$ is narrowed gradually as $V_{C S}$ is decreasing, then stops switching in time (soft-end function).

When switching is stopped, supplying to the voltage of the control IC's power supply $\mathrm{V}_{\mathrm{CC}}$ is also stopped, and then this voltage is reduced gradually by the power consumption of IC. And the output voltage $\mathrm{V}_{\mathrm{O}}$ is also reduced by the power consumption of the secondary side, but the output voltage $\mathrm{V}_{\text {Osub }}$ for the system control of the secondary side is stabilized by the DC-DC converter in the secondary side.

If $\mathrm{V}_{\mathrm{CC}}$ becomes under the threshold voltage of $\mathrm{V}_{\mathrm{BL}}$, the control IC starts charging $\mathrm{C}_{\mathrm{CS}}$ by constant current $\mathrm{I}_{\mathrm{CS}}$ and starts switching with the on period of $\mathrm{Q}_{1}$ limited by $\mathrm{V}_{\mathrm{CS}}$ (soft-start function).

As the switching is restarted, $\mathrm{V}_{\mathrm{CC}}$ and $\mathrm{V}_{\mathrm{O}}$ are increased. When $\mathrm{V}_{\mathrm{CC}}$ reaches the threshold voltage of $\mathrm{V}_{\mathrm{BH}}$, the control IC changes to soft-end function.

That is, this converter operates in intermittently switching with soft-start and soft-end function. The on period of $\mathrm{Q}_{1}$ and the peak of the resonant current increases and decrease gradually. And the slope of the resonant current envelope $\Delta \mathrm{I}_{\mathrm{Crp}} / \Delta \mathrm{t}$ is able to be adjusted with $\mathrm{C}_{\mathrm{CS}}$.

Therefore, this function is expected to suppress acoustic noise because it is known that a drastic change of a current through the transformer causes an acoustic noise [15].

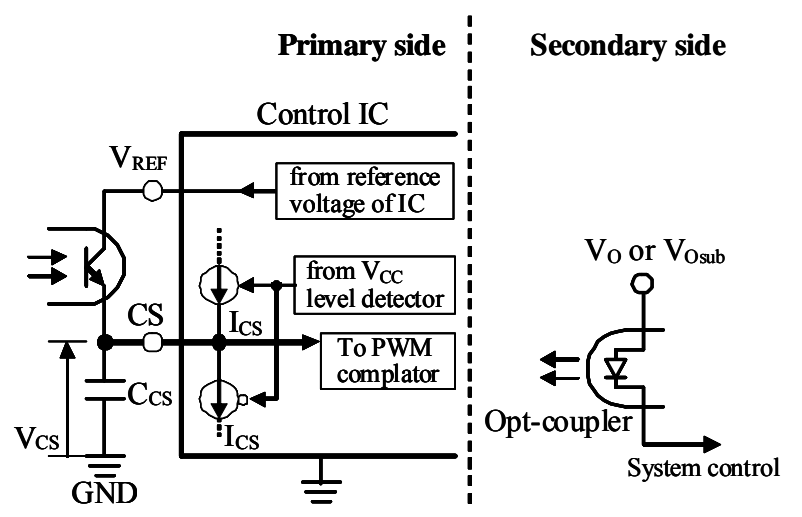

Fig. 5 Block diagram of control circuit (Related to standby function)

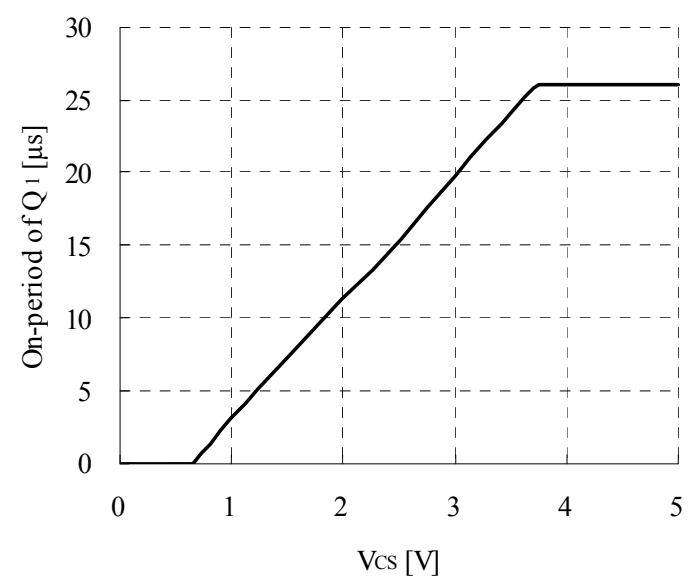

Fig. 6 On period of $\mathrm{Q}_{1}$ characteristic

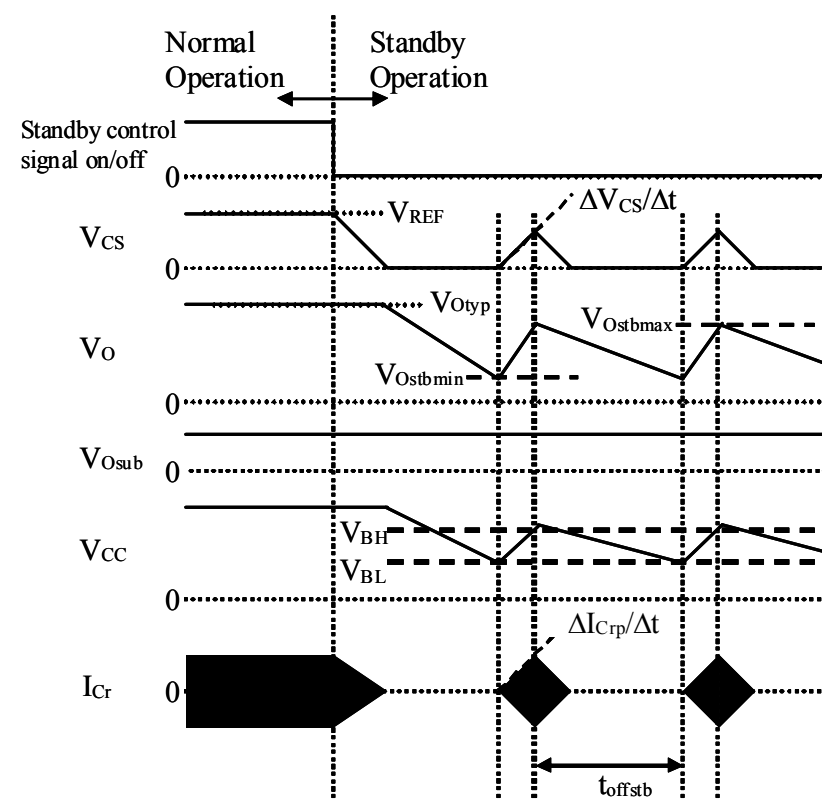

Fig. 7 Timing chart of standby mode. 
In the standby mode, as mentioned, $\mathrm{V}_{\mathrm{CC}}$ is regulated approximately between $\mathrm{V}_{\mathrm{BL}}$ and $\mathrm{V}_{\mathrm{BH}}$. Because the coupling between the winding $\mathrm{N}_{\mathrm{S} 1}, \mathrm{~N}_{\mathrm{S} 2}$ and $\mathrm{N}_{\mathrm{P} 4}$ is strongly, the output voltage of $\mathrm{V}_{\mathrm{O}}$ is proportional to the $\mathrm{V}_{\mathrm{CC}}$. So the output voltage $\mathrm{V}_{\text {Ostb }}$ in the standby state is given as:

$$
\begin{aligned}
& V_{\text {Ostb }}=\left(\frac{T_{N S 1}}{T_{N P 4}}\right) \cdot V_{C C} \\
& T_{N S 1}=T_{N S 2}
\end{aligned}
$$

where, $\mathrm{T}_{\mathrm{NS} 1}, \mathrm{~T}_{\mathrm{NS} 2}$ and $\mathrm{T}_{\mathrm{NP} 4}$ are the winding number of $\mathrm{N}_{\mathrm{S} 1}, \mathrm{~N}_{\mathrm{S} 2}$ and $\mathrm{N}_{\mathrm{P} 4}$.

To reduce standby power consumption in the secondary side, the maximum output voltage in the standby mode $\mathrm{V}_{\text {Ostbmax }}$ must be lower than the output voltage rating $\mathrm{V}_{\text {Otyp }}$ in the normal operation, and given as:

$$
V_{\text {Ostbmax }} \approx\left(\frac{T_{N S 1}}{T_{N P 4}}\right) \cdot V_{B H} \leq V_{\text {Otyp }}
$$

In addition, the minimum output voltage in the standby state $\mathrm{V}_{\text {Ostbmin }}$ must be higher than the minimum allowable input voltage of the secondary DC-DC converter $\mathrm{V}_{\text {Odcin }}$ so as to supply voltage continually to the system control.

$$
V_{\text {Ostbmin }} \geq V_{\text {Odcin }}
$$

$\mathrm{V}_{\text {Ostbmin }}$ is represented using $\mathrm{P}_{\text {Sstb }}$ which is power consumption in the secondary side in the standby mode.

$$
V_{\text {Ostbmin }}=\sqrt{V_{\text {Omax stb }}^{2}-\frac{2}{C_{C O}}\left(P_{\text {Sstb }} \cdot t_{\text {offtsb }}\right)}
$$

where, $\mathrm{C}_{\mathrm{CO}}$ is the capacitance of the output capacitor, $\mathrm{t}_{\mathrm{offstb}}$ is suspended period of intermittently switching in the standby mode and it is nearly equal with the fall time from $V_{B H}$ to $V_{B L}$ in $\mathrm{V}_{\mathrm{CC}}$. In this period, the control IC consumes almost constant current $\mathrm{I}_{\mathrm{CCstb}}$ from the capacitor $\mathrm{C}_{\mathrm{VCC}}$ which is connected with $\mathrm{N}_{\mathrm{P} 4}$ winding. Therefore, $\mathrm{t}_{\mathrm{offstb}}$ is given as:

$$
t_{\text {offstb }} \approx \frac{\left(V_{B H}-V_{B L}\right)}{I_{C C s t b}} \cdot C_{V C C}
$$

where, $\mathrm{C}_{\mathrm{VCC}}$ is the capacitance of $\mathrm{V}_{\mathrm{CC}}$.

\section{STANDBy Power CHARACTERISTICS}

\section{A. Standby power consumption characteristics}

Figure 8 shows experimental results of the power consumption characteristics. The experimental conditions are as follows: Input voltage $\mathrm{V}_{\text {in(ac) }}=100 \mathrm{~V}-240 \mathrm{~V}$, Output voltage rating $\mathrm{V}_{\text {Otyp }}=24 \mathrm{~V}$, Output Rating $\mathrm{P}_{\text {o(typ.) }}=144 \mathrm{~W}$, Resonant Capacitor $\mathrm{C}_{\mathrm{r}}=22 \mathrm{nF}$, Resonant Inductance $\mathrm{L}_{\mathrm{r}}=320 \mathrm{uH}$, Magnetizing Inductance $\mathrm{L}_{\mathrm{m}}=1.8 \mathrm{mH}$, Winding ratio of $\mathrm{T}_{\mathrm{r}} \mathrm{T}_{\mathrm{NP} 1}: \mathrm{T}_{\mathrm{NS} 1}\left(=\mathrm{T}_{\mathrm{NS} 2}\right): \mathrm{T}_{\mathrm{NP} 2}: \mathrm{T}_{\mathrm{NP} 3}: \mathrm{T}_{\mathrm{NP} 4}=59: 8: 5: 6: 6$, Capacitance of the output $\mathrm{C}_{\mathrm{CO}}=2200 \mathrm{uF}$, Capacitance connected to $\mathrm{V}_{\mathrm{CC}}$ winding $\mathrm{C}_{\mathrm{VCC}}=470 \mathrm{uF}$, Capacitance at $\mathrm{CS}$ terminal $\mathrm{C}_{\mathrm{CS}}=$ $0.56 \mathrm{uF}-2 \mathrm{uF}$, Charge and discharge current from CS terminal $\mathrm{I}_{\mathrm{CS}}= \pm 100 \mathrm{uA}$

It is confirmed that the standby power consumption $\mathrm{P}_{\text {in }}$ under no load condition i.e. $0 \mathrm{~mW}$ of the output power $\mathrm{P}_{\mathrm{O}}$ is below $60 \mathrm{~mW}$ at $100 \mathrm{~V} \mathrm{AC}$ input and $150 \mathrm{~mW}$ at $240 \mathrm{~V}$ AC input, respectively. When the $\mathrm{P}_{\mathrm{O}}$ is $50 \mathrm{~mW}$ under the light load condition, $\mathrm{P}_{\text {in }}$ is below $150 \mathrm{~mW}$ and $250 \mathrm{~mW}$ at $100 \mathrm{~V}$ and $240 \mathrm{~V} \mathrm{AC}$ input, respectively.

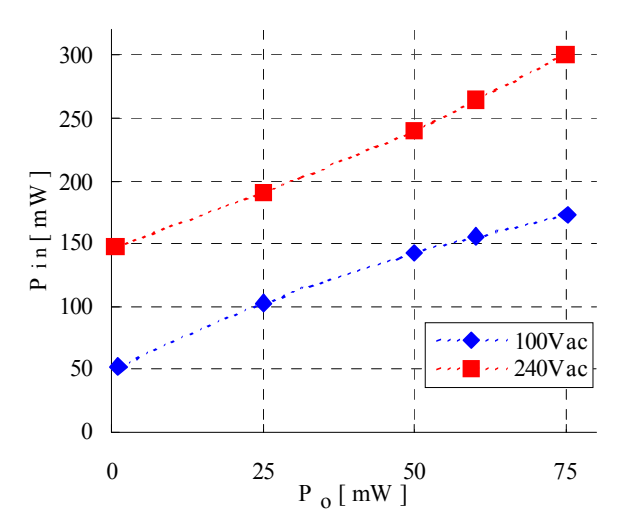

Fig. 8 Standby power consumption characteristics

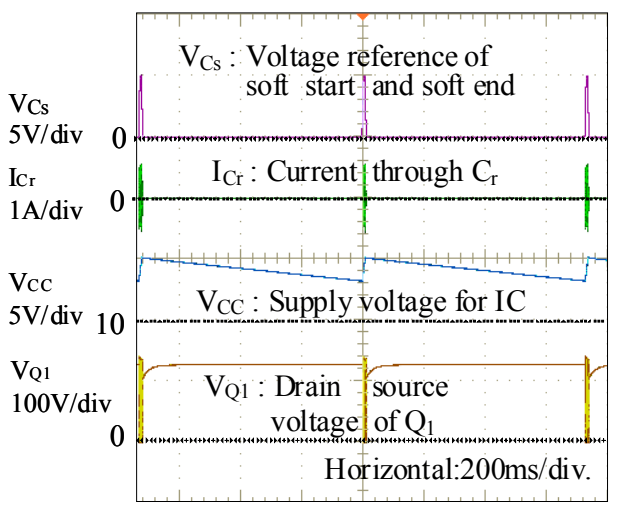

(a) Horizontal: $200 \mathrm{~ms} /$ div. $\left(\mathrm{V}_{\text {in }(\mathrm{ac})}=100 \mathrm{~V}\right)$

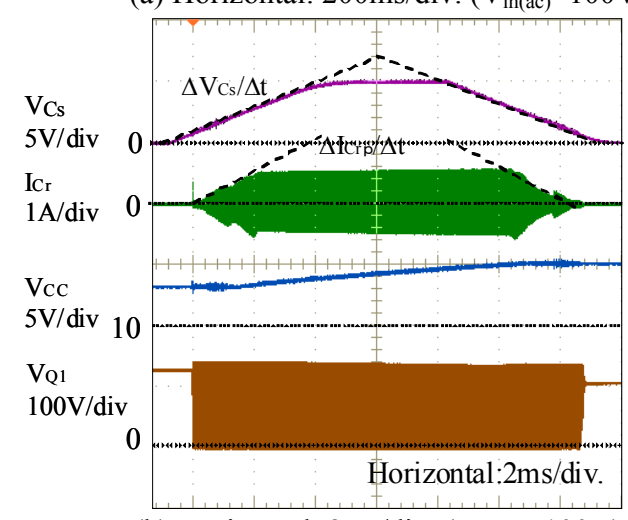

(b) Horizontal: $2 \mathrm{~ms} /$ div. $\left(\mathrm{V}_{\text {in(ac) }}=100 \mathrm{~V}\right)$

Fig. 9 Switching waveforms in the standby mode.

(a) $200 \mathrm{~ms} /$ div. and (b) $2 \mathrm{~ms} /$ div. i.e.

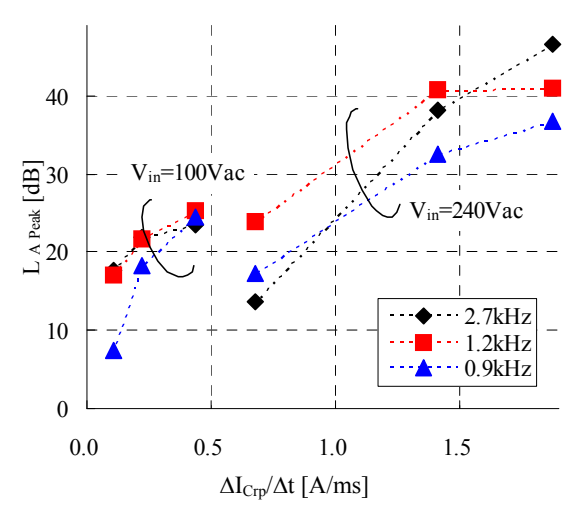

Fig. 10 A-weighted sound pressure characteristics in the standby mode 


\section{B. Acoustic noise characteristics}

Figure 9 shows the switching waveforms in the standby mode. In Fig.9 (b), the horizontal axis is enlarged 100 times. It is seen in this figure that the peak of $\mathrm{I}_{\mathrm{Cr}}$ is increased gradually as $\mathrm{V}_{\mathrm{Cs}}$ is increased in the soft-start and soft-end function. And the slope of the resonant current envelope $\Delta \mathrm{I}_{\mathrm{Crp}} / \Delta \mathrm{t}$ is determined by the slope of $\mathrm{V}_{\mathrm{Cs}}$.

Figure 10 shows experimental result of the sound pressure level characteristics, taking frequency of the acoustic noise $f_{A}$ as a parameter. The measurement values are adopted the Aweighted sound pressure level considering the equal loudness contour. These frequencies $f_{A}$ are selected from major 3 peaks of measured data. The measurement value of acoustic noise is represented as $\mathrm{L}_{\text {Apeak }}$. In Fig.10, it is confirmed that the Aweighted sound pressure i.e. acoustic noise from this converter becomes large with increase in $\Delta \mathrm{I}_{\mathrm{Crp}} / \Delta \mathrm{t}$. And the sound pressure level of the acoustic noise below $17 \mathrm{~dB}$ at $100 \mathrm{~V}$ AC input and $24 \mathrm{~dB}$ at $240 \mathrm{~V}$ AC input respectively is achieved.

\section{CONCLUSION}

Considering the acoustic noise compatibility, a novel reduction strategy of the standby power consumption is proposed and examined in the multi-oscillated current resonant DC-DC converter. As a result, this paper is conclude as follows,

(1) This converter is controlled by a combination of selfoscillation and a separated oscillation.

(2) This converter has eight states and four operating modes.

(3) In the novel standby control method, output voltage is controlled indirectly using the winding of the power supply for the control IC, which is coupled strongly to the secondary windings.

(4) In this converter, the standby power consumption below $60 \mathrm{~mW}$ at $100 \mathrm{~V} \mathrm{AC}$ input and $150 \mathrm{~mW}$ at $240 \mathrm{VAC}$ input at the no load respectively is achieved.

(5) The slope of the resonant current envelope $\Delta \mathrm{I}_{\mathrm{Crp}} / \Delta \mathrm{t}$ at the soft start and soft end function affects the A-weighted sound pressure i.e. acoustic noise from the converter.

(6) The sound pressure level of the acoustic noise below $17 \mathrm{~dB}$ at $100 \mathrm{~V}$ AC input and $24 \mathrm{~dB}$ at $240 \mathrm{~V}$ AC input respectively is achieved.

Optimization and analysis of the characteristics of standby mode, and more detail analysis of acoustic noise will be reported in our next paper.

\section{REFERENCES}

[1] V. Volperian and S.Cuk, "A complete dc analysis of the series resonance converter, " in IEEE PESC 1982, pp85-100.

[2] R. L. Steigerwald, "High frequency resonant transistor dc-dc converters," IEEE Trans. Ind. Electron., vol. IE-31, pp.181-191, May 1984.

[3] R. L. Steigerwald, "Analysis of a resonant transistor dc-dc converter with capacitive output filter," IEEE Trans. Ind. Electron., vol. IE-32, pp.439444, Nov. 1985.

[4] R. L. Steigerwald, "A comparison of half-bridge resonant converter topologies." IEEE Transactions on Power Electronics Vol. 3 No. 2, pp.174-182, April 1988.

[5] T. Duerbaum, "First harmonic approximation including design constants", INTELEC'98, pp.321-328, 1998.

[6] K. Morita "Novel Ultra Low-noise Soft Switching-mode Power Supply", INTELEC'98, pp.115-122, 1998.

[7] C. Chakraborty, M. Ishida, Y. Hori, "Novel half-bridge resonant converter topology realized by adjusting transformer parameters" IEEE Trans. on Industrial Electronics, vol. 49, no. 1, pp. 197-205, Feb. 2002.

[8] K. Kuwabara, H. Ota, "On the Output Increase of a Series Resonant DCDC Converter”, IEICE Technical Report, Vol.105, no.45, EE2005, pp.3540, 2005.

[9] K.-H. Yi, G.-W. Moon, "Novel Two-Phase Interleaved LLC SeriesResonant Converter Using a Phase of the Resonant Capacitor," IEEE Trans. on Industrial Electronics, vol. 56, no. 5, pp. 1815-1819, May 2009.

[10] A. K. S. Bhat, "Analysis and Design of LCL-Type Series Resonant Converter" IEEE Trans. on Industrial Electronics, vol. 41, no. 1, pp. 118-124, Feb. 1994

[11] K. Jin, X. Ruan, "Hybrid Full-Bridge Three-Level LLC Resonant Converter - A Novel DC-DC Converter Suitable for Fuel-Cell Power System," IEEE Trans. on Industrial Electronics, vol. 53, no. 5, pp. 1492 1503, Oct 2006.

[12] J.A. Sabate, M.M. Jovanovic, F.C. Lee, R.T. Gean, "Analysis and design-optimization of LCC resonant inverter for high-frequency AC distributed power system," IEEE Trans. on Industrial Electronics, vol. 42, no. 1, pp. 63-71, Feb 1995

[13] M. Gekinozu, K. Kuroki, K. Mori, T. Fujita "Self-oscillated type current resonant DC/DC converter”, IEICE Technical Report, EE99-58, pp.3338. 2002.

[14] Y. Nishikawa, T. Nozawa, S. Igarashi, K. Kuwahara, N. terasawa "Multi-oscillated Current Resonant Converter", Annual Conference Record of EEEJ, Vol.4, pp.157-158, 2002.

[15] Y. Nishikawa, T. Nozawa, S. Igarashi, K. Kuwahara, N. Nozawa, H. Ota "A control method that reduce the conversion loss at a light load", Annual Conference of Japan, Industry Application Society, pp.631-632, 2002.

[16] R.Araki, O. Matsuo, H. Ota, M. Tuji, Y. Ishizuka, H. Matsuo "Static Analysis of Multi-Oscillated Current Resonant Type DC-DC Converter", IEICE Technical Report, EE2006-31, pp13-18, 2006.

[17] T. Sato, R. Araki, H. Ota, N. Higashi, Y. Ishizuka, H. Matsuo "Power Efficiency Analysis of a Multi-Oscillated Current Resonant Type DCDC Converter”, IEEE PESC'08, pp.1646-1650, 2008.

[18] T. Sato, H. Matsuo, H. Ota, Y. Ishizuka, N. Higashi, "Power Efficiency Improvement of a Multi-Oscillated Current Resonant Type DC-DC Converter Power Efficiency Analysis of a Multi-Oscillated Current Resonant Type DC-DC Converter', IEEE INTELEC'09, PC15-1, pp.1-5, 2009. 